\title{
Curricular Reform: Changing from Disciplined-Based to Competency -Based Framework
}

\author{
Manuel Sandoval Martínez, ${ }^{1, *}$, Maricela García Avalos ${ }^{1}$, Gladys del C Velázquez López ${ }^{1}$ \\ \& Gerardo E Sepúlveda Palacios ${ }^{1}$ \\ ${ }^{1}$ Dept. of Petroleum Engineering, Carr. Fed. Malpaso-El Bellote, Km 171. Monte Adentro, \\ Paraíso, Tabasco, México
}

*Corresponding author: Dept. of Petroleum Engineering, Carr. Fed. Malpaso-El Bellote, Km 171. Monte Adentro, Paraíso, Tabasco, México. Tel: 52-01-933-110-0382. E-mail: manuelsandova1804@gmail.com

Received: December 27, 2014 Accepted: January 30, 2015 Published: February 5, 2015

doi:10.5296/ije.v7i1.6835 URL: http://dx.doi.org/10.5296/ije.v7i1.6835

\begin{abstract}
The results of the modified curriculum for the course "Introduction to Engineering" taught during the preparatory courses at the Universidad Politécnica del Golfo de México are presented. The modification was made to thematic content, the learning outcomes, the distribution of theoretical and practical hours (35\% and $65 \%$ respectively) and the teaching strategy (using Krulik \& Rudnick method and context problems), focusing on competency-based framework. Analysis of data indicates that various objectives were achieved with this reform, which the previous curriculum were not met, such as decreasing failure/dropout rate from $40 \%$ to $15 \%$, greater involvement of students in lessons, development of logical-mathematical skills, problems solving through a systematic procedure skills, among other reasoning. This leads us to believe we have made a transition from a declarative knowledge to a functional one.
\end{abstract}

Keywords: Curricular reform, Competency base framework, Context problems, Problem solving strategy 


\section{Introduction}

Among the new university rules, curriculum and programs of study must have a competency approach, mainly in the curricular issue which seeks to change the way of teaching and take lessons in the classroom (Cepeda, 2004). This change involves various factors such as the mentality and willingness of teachers to leave their state of comfort within traditional model; student's philosophy who only conforms to attend classes and thinks it is the teacher's responsibility to find the right strategies to acquire the knowledge they need, and if they don't get them, they blame the teacher of their failure; the educational authorities' support to both teachers and students so they have the necessary conditions to carry out this new way of teaching. Competency-based Education (CBE) is student-centered (Tobon, 2010) and requires three basic attitudes (Bernal, 2006): collaboration, autonomy and responsibility. This indicates that students will be responsible for their own learning (they become active subjects) for that reason, they must learn to work collaboratively and to this end, it is required that teacher promote a good learning environment motivating them to achieve that goal.

In turn, they should not depend on the teacher for all activities to be performed, that is to say they must reach a certain level of autonomy and self-confidence to develop their professional skills. For this reason, planning of subjects should be done in different way than the traditional one; objectives should be aimed at developing generic and specific skills, taking into account their prior knowledge; thematic contents should be suitably selected in both quantity (tending to decrease) and quality and they should directly relate to their career, fact that reveals that curricular design should be done thinking on students and not on teachers.

De Miguel Díaz (2004) point out that the procedures that will be used in the development of the teaching process must be specified in order to promote a methodological change from the teacher-centered teaching to student-centered one. A very important aspect to consider in the curricular design is that learning outcomes (objectives of each unit) must be addressed to achieve functional knowledge. For example, using verbs such as accentuate, identify, list, represent, among others, only takes to declarative knowledge, which does not make much sense on university where students must develop their rational potential. To acquire functional knowledge the most appropriate verbs are analyze, evaluate, synthesize, create, etc. According to Tyler (1949), the most useful way of making objectives is to express them in terms that, at the same time, identify the type of conduct that aims generate and the content of sector where that behavior will apply.

Since the late $40^{\prime} \mathrm{s}$ it began to form the idea of the concept of competence, based on this model, it begins to speak of development of coexistence, personal and communication competences. According to Bernal (2010) and Tobón (2006), being competent means to be able to perform effectively and responsibility in face of problems, then the purpose of higher education is to produce competent individuals and to achieve this it requires a curricular design made in such a way that ensures the gradual and systematic competence's construction. Within the curricular design, number of activities are indicated by the presential and non-presential hours, both theoretical and practical; According to CBE model, number of theoretical hours should range from $30-35 \%$ and practical hours from $65-70 \%$ (Bernal, 2006; 
Yániz, 2008). Similarly, the number of students per classroom should range maximum, between 30 and 35 with adequate spaces to teach the lessons. In Figure 1, the process used to make the new curricular design (Carson, Bloom, 2005) of the course Introduction to engineering is shown.

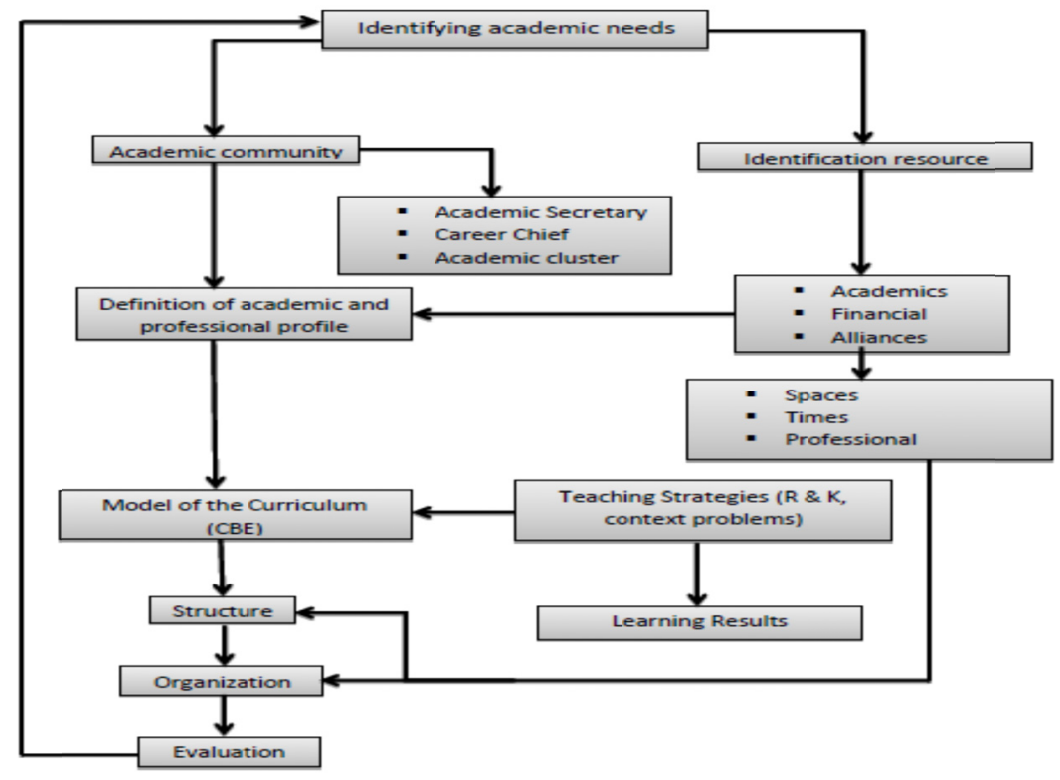

Figure 1. Curricular Design Cycle

The motivation for the development of this work is on the following problem: Since its inception the Universidad Politécnica del Golfo de México (UPGM) has offered to its new students a preparatory course with late 8 weeks and an academic load of 8 hours per day. During that period, students were enrolled to 7 subjects which were: Introduction to Engineering, Introductory Physics, Basic English, Basic Offimatic, learning techniques and strategies, Logical Mathematical Reasoning and Oral and written communication.

According to the model $\mathrm{CBE}$, for each subject four evidences are applied: knowledge, performance, product and attitude. This means that the students were subjected to two intense months of academic work during which at least 21 evidences should be submitted, being allowed two recoveries. From 2012 to date it was observed that the level of stress to which students were subjected was very high, resulting in a high dropout/failure rate (about 40\%), this meant that for each 200 Petroleum Engineering (IP) aspiring students at least 40 students failed/deserted. Furthermore, the teaching style had a trend toward the traditional model, meaning that the practical issues that each learning unit should have were not taken into account because the teachers used traditionalist assessment and exercises. Another point to consider is that teachers themselves decided which topics could be analyzed in more detail and which ones could not, so there was no homogeneity in learning groups available (usually four) and they worked with classic textbooks such as Baldor (2011) or Sowkowski-Cole (2009), focusing on the simple mathematical solution without dealing with concrete or practical career applications cases (Zavala, 2007). While this type of exercises has a well-organized structure and a process of predictive solution, it doesn't drive them to develop 
skills to solve more complex problems (Johansen, 2010; Fábio et al, 2014).

Based on these observations, academic cluster decided to make several structural changes in the preparatory course (See Appendix I); in particular in this work we will focus on a reform in the course Introduction to Engineering.

\section{Framework}

\subsection{Comparison between curriculum 2008 and 2014}

\subsubsection{Curriculum 2008}

In this section we'll discuss similarities and differences between curriculum 2008 and curriculum 2014. We start with Table 1 which shown learning outcomes about curriculum 2008 and 2014. One of the problems in curriculum 2008 is that Unit I is limited just to identify the numeric system which students just reach a declarative knowledge and poor functional knowledge; this unit indicates working with real and complex numbers, however the last one is not commonly used in bachelor's degree (particularly on petroleum engineering). On Unit II, students have to learn to factorize and identify different equations, obtaining a declarative knowledge again; also there are others topics such as analysis of linear equations system and inequalities that we consider not very important in this course.

Table 1. Comparison among Learning Units

\begin{tabular}{|c|c|}
\hline Curriculum & 2014 \\
\hline Unit I & $\begin{array}{l}\text { Identify distinct numerical systems and Analyze real numbers properties for } \\
\text { implement algebraic operations using real their application in engineering's } \\
\text { numbers and complex numbers to resolve problem solution using elemental } \\
\text { problems. }\end{array}$ \\
\hline Unit II & $\begin{array}{l}\text { Factorize algebraic expressions and Disarrange second } \\
\begin{array}{ll}\text { identify the distinct kind of equations for } \\
\text { their application in problem solutions. }\end{array} \\
\begin{array}{ll}\text { factorize laws to resolve linear } \\
\text { problems and second order } \\
\text { problems. }\end{array}\end{array}$ \\
\hline Unit III & $\begin{array}{l}\text { Represent coordinate pairs in the Cartesian Analyze linear function behavion } \\
\text { plane, identify straight equation, and no linear function using graphic } \\
\text { circumference, ellipse, parable and methods to modeling engineering's } \\
\text { hyperbola on their different representation phenomena. } \\
\text { and translate the slope as rate of change in } \\
\text { order to interpret engineering problem } \\
\text { solutions. }\end{array}$ \\
\hline Unit IV & $\begin{array}{l}\text { Identify trigonometric functions graphics Apply trigonometry's identities } \\
\text { and implement basic operations using trough elemental functions in order } \\
\text { trigonometry's identities in order to solve to simplify basic algebraic } \\
\text { engineering problems. } \\
\begin{array}{l}\text { operations in engineering problems } \\
\text { solving. }\end{array}\end{array}$ \\
\hline
\end{tabular}


Number of topics included in this unit are very high (14) covering $47 \%$ of total content in the subject and number of class time is low (less than $1 \mathrm{hr}$ per theme). Learning outcomes in Unit III indicate that students have to represent, in Cartesian plane, any coordinate pair and identify some geometric equations; on this way we cannot guarantee that students could analyze and resolve context problems. As point of view of curriculum design (Schmal and Ruíz-Tagle, 2008; Bobbit, 1918), level demand to Barchelor's degree students have to be high, but with curriculum 2008 is very difficult reach this aim because work load is heavy. Sudsomboom (2007) said "If specific competencies are not focused in the curriculum design philosophy, the products of the engineering technology program may not be "work-ready" and therefore not readily accepted by the industry. Therefore, to reduce the unemployment and 'under employment' levels, it becomes necessary to consider 'occupation-specific competencies' in the curriculum designs".

For this reason we modified curriculum 2008 with the intention to improve the learning process, the content and the teaching methodology.

\subsubsection{Curriculum 2014}

We modify the content and learning knowledge on curriculum 2008 to become in a new curriculum (20014) more active and demanding for students in order to improve their academic level, math reasoning and develop generic and specific abilities. We eliminate complex numbers in unit I, but we add notable products and partial fractions, also number of class hours in this unit increase (16\% to $18 \%$ ) and number of themes decrease from $20 \%$ to $16 \%$. Learning outcomes change its verb from identify to analyze, in this way students have to do a deeper study about real numbers, notable products and partial fractions. Unit II changed considerably, we reduce number of topics from $47 \%$ to $27 \%$ and, number of class hours increase from $28 \%$ to $39 \%$ in this path professor and students could analyze the content with more detail, principally factorization; in this case we use the verb disarrange in order to include notable products as tool of factorization. In other side, Unit III indicates analyze the behavior of different functions (not only identify) and especially understand that those functions are useful to modeling various natural phenomena; topics decrease from $17 \%$ to $13 \%$ and number of hours decrease from $28 \%$ to $21 \%$. In Unit IV, the verb changed from identify to apply including explicitly working with engineering problems and students must have the appropiate background they learned during the curse; number of topics and number of class hours did not change with respect to curriculum 2008. So, the content for our subject decrease $30 \%$ (from 30 to 20 ) but total number of class hour did not change (60hrs). It was possible to make a better distribution in the academic load both students and professors having enough time to analyze all topics deeply.

\section{Theoretical/Practical Hour's Distribution}

Now, we'll talk about theoretical/practical hours in the curriculum between both 2008 and 2014. According to Competency framework we have to pass from disciplined-based, using principally teaching Lecture $(80 \%)$ and low practical hour $(20 \%)$, to competency-base 
curriculum which use high practical hour (80\%) and low teaching Lecture (20\%). Nonetheless, since 2006 the UPGM have had a curriculum with tendencies to traditional teaching because theoretical hours spend $45 \%$ of the content and practical hours have $55 \%$ (See Table 2), this distributions is far to fulfill with competency framework. In the current curriculum (2014) hours distributions change in the following way: theoretical hours $35 \%$ and practical hours $65 \%$, which is much more close to competency framework.

Table 2. Theoretical/Practical Hour's Distribution

\begin{tabular}{ccccccc}
\hline Curriculum & \multicolumn{3}{c}{2008} & \multicolumn{3}{c}{2014} \\
\cline { 2 - 7 } Unit & Theor & Pract & Percentage & Theor & Pract & Percentage \\
\hline I & 6 & 4 & 16.6 & 4 & 7 & 18.3 \\
II & 7 & 10 & $\mathbf{2 8 . 3}$ & 7 & 16 & $\mathbf{3 8 . 3}$ \\
III & 7 & 10 & 28.3 & 5 & 8 & 21.6 \\
IV & 7 & 9 & 26.6 & 5 & 8 & 21.6 \\
Percentage & 45 & 55 & 100 & 35 & 65 & 100 \\
\hline
\end{tabular}

As we can see on Table 2, academic hours are better distributed in curriculum 2014 because, for example, Unit II needs more time for adequately work, so we increase numbers of class hours (38.3\%) nevertheless, curriculum 2008 had 28.3\%.

With these changes didactic sequences could have a best effectiveness because professor/students could analyze the themes carefully. In order to fortify our proposal we changed the teaching methodology and we propound three fundamental actions:

a) Use Rudnick\&Krulik (R\&K) method to solve context problems

b) Design and use context problem focused to petroleum engineering

c) Train professors in the new methodology and new curriculum

We will describe briefly those actions. R\&K method (Rudnick and Krulik, 2008), is a process or set guidelines that a person applies to various situations and consist in five steps: read, explore, select a strategy, solve and extend. This method shown useful for students because they could resolve some problems orderly, clearly and confident (Sandoval et al, 2014a). Shoenfield (2013) point out that success in problem solutions depend, among other factors, of strategies used for each person; Reif (1981) point out that problem comprehension starts making a description of problem which helps in the search for an appropriate solution. Polya and Hardin (2002) developed a model to resolve problems in a systematic way similar to $\mathrm{R} \& \mathrm{~K}$, but we decided to work with $\mathrm{R} \& \mathrm{~K}$ because is more appropriate for university students being that step five (extend) allows a better visualization about problem solution under different initial conditions. The reason for what we decided working in this path is because some research (McCalla, 2003; Lorenzo, 2005; Lloyd, 2014) indicates that those students who utilize an specifics procedure obtain better outcomes and obtain upper confidence that those who not. On this base, we put into practice R\&K method to solve complex problems and we find that at the beginning it was hard for students to work this way but, step by step, they understood the process and improved their abilities considerably and they became more 
confident and sure in each steps.

We designed several context problems focused to petroleum engineering (Sandoval, et al $2014 \mathrm{~b}$ ) and the propound is to use $\mathrm{R} \& \mathrm{~K}$ method, these context problems tend to demand students and professors a best effort in order to achieve a functional knowledge. In order to fulfill with learning outcome those professors whom will teach this subject have to take the training teacher course (30 hrs) and achieve all learning outcome and learn to use R\&K method. Finally, we applied a Likert survey to evaluate the new curriculum (See Appendix 2) participating 72 students from a population of 160 students. Analysis of data point out that $90 \%$ of students consider that the new curriculum cover totally their expectations, $88 \%$ indicates that context problems were challenging, $80 \%$ considers that their knowledge improve working with this methodology. In the other side, redesign in the curriculum consider implicitly reduce the fail index, as we indicated in section I work loud in curriculum 2008 provoked several problems in students' learning process and their achievements were poor. With the new curriculum we have observed students have had enough time to accomplish the evidences to evaluate their academic performance so, index failure decrease from $40 \%$ to $15 \%$. These analyses indicate that with curriculum 2014 students and professor could work and study all topics deeply and provoke a functional knowledge.

\section{Conclusion}

With the reforms made to the curricular design of the course Introduction to Engineering, a significant improvement was found in academic environment between both teachers and students. Some of the major achievements of this new form of work include the following:

a) The pace of work was done in a more dynamic way

b) The class level of participation increased significantly (approximately $80 \%$ of the students actively intervened during class, since in the previous model the level was around 30\%)

c) The level of motivation to work with context problems was significant ( $86 \%$ acceptance)

d) The rate of dropout / failure decreased from $40 \%$ to $15 \%$

e) The level of students' reasoning significantly improved (80\%)

f) The development of skills to work collaboratively increased

g) The development of logical-mathematical skills was gradually increased

These results indicate that the changes made to this subject have been satisfactory and established goals were reached. The fact of properly choose the verbs in the construction of learning outcomes makes the teaching-learning process more dynamic, even more, it was achieved to transcend from a declarative knowledge to a functional one (which were one of the objectives); well as the change in educational strategy (use of $\mathrm{R} \& \mathrm{~K}$ in complement with context problems) has shown to be very effective for students to learn how to solve problems more efficiently and more confidence, sample of this is the reduction of the fail rate. The 
redistribution of the number of hours assigned to each unit has allowed the subjects could be analyzed in greater depth; it has been noticed that in particular the topic of factorization were properly understood as they had the time for it (with an low rate of failure), so does the rest of the learning units. Overall, we consider this curricular reform as a success because the problems that students had with the curriculum 2008 have been overcame, however, it is currently still working on improving the context problems and, students who participated in these courses will be under observation for knowing the retention of the knowledge acquired, at least during the first third of the year.

\section{Acknowledgement}

This work was sponsored by Universidad Politécnica del Golfo de México through Research and Posgrado department.

\section{References}

Baldor, A. (2008). Algebra. Patria, México.

Bernal, J.L. (2006). Curricular design on university teaching by ECTS. Colection 06, Instituto de Ciencias de la Educación, Universidad de Zaragoza.

Bernal, J.L. (2010). Norms to design an subject by ECTS perspective. Universidad de Zaragoza. Retrieved from http://webdiis.unizar.es/ jamarro/pipg/documentos/2007

Bobbitt, F. (1918). The curriculum, Illinois. The University of Illinois Library.

Carson, M. P., \& Bloom, I. (2005). The cyclic nature of problem solving: an emergent: Multidimensional problem solving framework. Educational Studies in Mathematics, 58, 45-75. http://dx.doi.org/10.1007/s10649-005-0808-x

Cepeda, J. M. (2004). Competency- based model methodology. Editorial Tópicos Culturales. México.

De Miguel Diaz, M. (2004). Adjusment of plan studies to Europe process convergence. Dirección General de Universidades. Ministerio de Educación, Cultura y Deporte.

Fábio, D. Ribeiro, L. Batista, D., \& Ribeiro, R. (2014). Using learning principles base on problem solving on science fair context. Revista electrónica de enseñanza de las ciencias, 13, 292-317.

Jonassen, D. H. (2010). Research issues in problem solving. The 11th International Conference on Education Research New Educational Paradigm for Learning and Instruction. Retrieved from http://www.aect.org/publications/whitepapers/2010

Krulik, S., \& Rudnick, J. A. (1987). Problem solving: A handbook for teachers (2nd ed.). Boston: Allyn and Bacon. 
Likert, R. (1932). A Technique for the Measurement of Attitudes. Archives of Psychology, No.140.

Lloyd M. Mataka, William W. Cobern, Megan L. Grunert, Jacinta Mutambuki \& George Akom. (2014). The Effect of Using an Explicit General Problem Solving Teaching Approach on Elementary Pre-ServiceTeachers' Ability to Solve Heat Transfer Problems. International Journals of Education in Mathematics, Science and Technology, 2(3), 164-174.

Lorenzo, M. (2005). The development, implementation and evaluation of a problem solving heuristic. International Journal of Science and Mathematics Education, 3, 33-58. http://dx.doi.org/10.1007/s10763-004-8359-7

McCalla, J. (2003). Problem solving with pathways. Journal of Chemical Education, 80, 9298. http://dx.doi.org/10.1021/ed080p92

Polya, G. (1957). How to solve it.(2nd ed). Princeton University Press.

Reif, F. (1981). Teaching problem solving: A scientific approach. The Physics Teacher, 19, 310-316. http://dx.doi.org/10.1119/1.2340790

Sandoval, M., García, M., \& Velazquez, G (2014a). Developing abilities on factorization using context problem. Congreso internacional de Investigación de la AcademiaJournals.com.

Sandoval, M., García, M., \& Velazquez, G. (2014b). Introducción al Algebra, geometría y trigonometría. Edumed, España.

Schmal R, Ruì-Tagle, A. (2008). A method to curriculum design focused to competency model. Revista Chilena de Ingeniería, 1, 147-158.

Schoenfeld, A. (2013). Reflections on Problem Solving Theory and Practice. Retrieved from http://www.math.umt.edu/tmme

Sudsomboon, W., \& Anmanatarkul, A. (2007). Competency-based curriculum development on automotive technology subjects for mechanical technology education. A paper presented at the 5th international conference on developing real-life learning experiences, Thailand. Retrieved from http://www.kmutt.ac.th/rippc/pdf

Swokowski, E. y Cole, J. (2009). Algebra and trigonometry with geometry.(12ed). CENGANE learning, México

Tobón, S. (2006). Competency based model background. Talca: ProyectoMesesup. Retrieved from http://www.uv.mx/facpsi/proyectoaula/documents

Tobón, S. (2010). Teaching in competency: complex think, curriculum design and didactic. Colombia: Ecoe.

Tyler, R. (1970). Basic principles about curriculum. Buenos Aires: Troquel.

Yániz, C. (2008). The competencies in university curriculum: implications to design the 
teaching and for teacher training. Revista de Docencia Universitaria, 1, 1-13

Zabala, A. y Arnau, L. (2007). Teaching competencies. Aula de Innovación Educativa, 161, $40-46$.

\section{Appendix}

Appendix 1. Comparison between Curricular content 2008 vs 2014

\begin{tabular}{|c|c|c|c|c|}
\hline Unit & I & II & III & IV \\
\hline 2008 & $\begin{array}{l}1.1 \text { Introduction to } \\
\text { algebra } \\
\text { 1.2 Real numbers } \\
1.3 \text { Fraction numbers } \\
\text { properties } \\
1.4 \text { Exponents } \\
\text { 1.5Algebraic } \\
\text { expressions } \\
1.5 \text { Complex number }\end{array}$ & $\begin{array}{l}\text { 2.1 Common term factorization } \\
\text { 2.2 Bracket factorization } \\
\text { 2.3 Perfect square trinomial } \\
\text { 2.4 Square differences } \\
\text { 2.5 Special cases } \\
\text { 2.6 Trinomial in the form } \\
\mathrm{ax}^{\wedge} 2+\mathrm{bx}+\mathrm{c} \\
\text { 2.7 Perfect cube of binomial } \\
\text { 2.8 Add and subtraction of } \\
\text { cubes } \\
\text { 2.9 Linear equation solving } \\
\text { 2.10 Square equation solving } \\
\text { 2.11 Synthetic division } \\
\text { 2.12 Inequalities }\end{array}$ & $\begin{array}{l}\text { 3.1 Straight equation } \\
\text { 3.2 Parables } \\
\text { 3.3 Circumferences } \\
\text { 3.4 Ellipses } \\
\text { 3.5 Hyperbola }\end{array}$ & $\begin{array}{l}\text { 4.1 Trigonometric functions } \\
\text { 4.2 Trigonometric equations } \\
\text { 4.3 Trigonometric identities } \\
4.4 \text { Add and subtraction } \\
\text { formula } \\
\text { 4.5 Multiples angles formula }\end{array}$ \\
\hline 2014 & $\begin{array}{l}\text { 1.1 Real numbers } \\
\text { 1.2 Exponent laws } \\
1.3 \text { Operations with } \\
\text { fraction numbers } \\
\text { 1.4 Notable products } \\
\text { 1.5 Partial fractions }\end{array}$ & $\begin{array}{l}\text { 2.1 Factorization } \\
\text { 2.2 Common factor } \\
\text { 2.3 Perfect square trinomial } \\
\text { 2.4 Square differences } \\
\text { 2.5 Trinomial in the form } \\
\mathrm{ax}^{\wedge} 2+\mathrm{bx}+\mathrm{c} \\
\text { 2.6 Linear equations } \\
\text { 2.7 Square equations } \\
\text { 2.8 Inequalities }\end{array}$ & $\begin{array}{l}3.1 \text { Equations and } \\
\text { graphics of straight } \\
3.2 \text { Equations and } \\
\text { graphics of parable } \\
3.3 \text { Equations and } \\
\text { graphics of circles } \\
3.4 \text { Graphics of } \\
\text { rational functions }\end{array}$ & $\begin{array}{l}\text { 4.1 Trigonometric functions } \\
\text { 4.2 Logarithm and } \\
\text { exponential function } \\
\text { 4.3 Trigonometric identities } \\
\text { 4.4 Graphics of trigonometric } \\
\text { functions } \\
\text { 4.5 Graphics of logarithm } \\
\text { and exponential functions }\end{array}$ \\
\hline
\end{tabular}




\section{Macrothink}

Appendix 2. Likert survey.

Dear student, answered the following survey, according the weighting below

1. Strong disagreement

2. Disagreement

3. Neutral

4. Agree

5. Strong agree

\begin{tabular}{|c|c|c|c|c|c|}
\hline Statements & 1 & 2 & 3 & 4 & 5 \\
\hline 1. The course cover all my expectative & & & & & \\
\hline 2. Context problems were challenging & & & & & \\
\hline 3. My learning improve working with context problems & & & & & \\
\hline 4. Context problems extend my overview about my career & & & & & \\
\hline 5. I will work again with this methodology in other courses & & & & & \\
\hline
\end{tabular}

\section{Copyright Disclaimer}

Copyright for this article is retained by the author(s), with first publication rights granted to the journal.

This is an open-access article distributed under the terms and conditions of the Creative Commons Attribution license (http://creativecommons.org/licenses/by/3.0/). 